\title{
Dynamic Evolutionary Game Model for High Quality Development Between Governments and Logistics Enterprises
}

\author{
Yingdong $\mathrm{Ji}^{1}$ and yanqing $\mathrm{GaO}^{2, *}$ \\ ${ }^{1}$ School of Management Science and Engineering, Shanxi University of Finance and economics, Taiyuan, China \\ 030006 \\ ${ }^{2}$ School of Business Administration, Shanxi University of Finance and Economics, Taiyuan, Shanxi, China 030006 \\ ${ }^{*}$ Corresponding author. Email: ${ }^{1} 13934564176 @ 126 . c o m ;{ }^{2} 1573754567 @ q q . c o m$
}

\begin{abstract}
Based on the assumption of the limited rationality of the government and logistics enterprises, the evolutionary game replication dynamic model of the governments and logistics enterprises on the high-quality development is established. The game method analyzes the behavior of the government, which is about the government's support for the high-quality development of logistics enterprises. This paper explores the dynamic evolution process of game behavior, and discusses in detail the evolution of each parameter and how the parameters are set to form a stable strategy. The results show that the government and logistics enterprises pay more attention to high-quality development behaviors, the logistics enterprises are more willing to implement high-quality development. Governments and logistics enterprises can achieve a win-win situation in this state.
\end{abstract}

Keywords: High quality development, Replication equation, Dynamic game.

\section{INTRODUCTION}

The rapid development of e-commerce has promoted the vigorous development of the logistics industry, and logistics enterprises have also become the backbone of high-quality development. Shanxi Province in China introduced a response policy to promote the high-quality development of logistics enterprises. In recent years, logistics has also achieved certain development as a key construction industry. However, it still has problems such as low level, low technology and extensive operation. In view of the high-quality development of logistics enterprises, through the literature review, it is found that logistics enterprises mainly achieve high-quality development from the four objectives.

(1)Industrial structure optimization has shifted from relying on resources and manpower-driven industries to relying on technology inputs and knowledge inputs to produce or provide products and services of high quality. Gao[1] pointed out that the management of the concentration of logistics enterprises can promote the optimization; $\mathrm{Li}$ [2] believes that the quality of enterprise team management affects the improvement of enterprise competitiveness;Wang[3]found that there are problems in the performance management of $R \& D$ personnel Greatly restrict the further development of the enterprises.

(2)The transformation of economic benefits is the cost of the enterprise from high to low, and the efficiency of the corresponding enterprise is from low to high. Wei [4] pointed out that the policies promulgated by the state have a great impact on the development of corporate finance. He [5] pointed out that logistics enterprises can accelerate the innovation of supply chain.

(3)The transformation of the ecological environment is a transition from a high-pollution and high-emissions development model to a sustainable, environmentally-friendly economy. Niu [6] pointed out that effective implementation of green logistics management is the key to achieving a green and low-carbon environment; Li[7] pointed out that logistics enterprises need to establish the goal of developing green logistics in order to achieve long-term and 
sustainable development; Ma[8] found the necessity of logistics enterprises to implement green logistics.

(4)The development effect must achieve the transformation of the people's needs for a better life. The development of logistics enterprises should further highlight the sense of gain of the people, including happiness and dignity.

By reading the relevant literature, it is known that there are not many literatures on the high-quality development of government and logistics enterprises according to dynamic evolutionary games. Under the premise of bounded rationality, this paper uses evolutionary game theory to study the game between government and logistics enterprises on high-quality development behavior. It is a dynamic analysis of the game and is also based on bounded rationality. This is the greatest advantage of evolutionary game theory over other game theories [9].

\section{EVOLUTIONARY GAME MODEL}

The basic assumptions of the evolutionary game model:

Hypothesis 1: The game subject of the evolutionary game is randomly drawn from the two camps, and they will continue to repeat the game. This article refers to the interest groups of both sides of the game as the logistics enterprise and the government.

Hypothesis 2: Logistics enterprises can choose to implement and do not implement strategy. Governments can choose encourage and do not encourage strategy.

Hypothesis 3: The premise of evolutionary game theory is that both sides of the game are playing on the basis of limited rationality, and the ultimate goal of both sides is to maximize their own interests. It is assumed that the proportion of the game strategy in which the government game subject chooses "encourage" is $\mathrm{x}$; the ratio of the "implement" strategy for the logistics enterprise's game subject is $\mathrm{y}$.

Assume that the following variables represent the following meanings:

(1)When the government does not encourage logistics enterprises and logistics enterprises do not actively implement high-quality development behavior, they will continue to continue in the current situation. In a short period of time, they can achieve certain benefits. It is assumed that the government's income is $\mathrm{U}$, and the logistics enterprise's income is $\mathrm{V}$.

(2)When the government encourages the high-quality development and the logistics enterprises also choose high-quality development, they can create more revenue. Assuming that the total revenue generated at this time is $\mathrm{U}+\mathrm{V}+(\mathrm{m}+\mathrm{n})$, the government's income is $\mathrm{U}-\mathrm{c}+\mathrm{m}$, the profit obtained by the logistics enterprise is $\mathrm{V}+\mathrm{c}+\mathrm{n}$, where $\mathrm{c}$ is the cost of financial support policy. M,n is the "excess profit" obtained by high quality development. $\mathrm{m}$ represents the governments' income.n is the increase of logistics enterprises through the green optimization, industrial structure optimization and other high-quality development of enterprises.

(3)When the government encourages the high-quality development, the logistics enterprises have not carried out high-quality development. The total return is still $\mathrm{U}+\mathrm{V}$, the government's income becomes $\mathrm{U}-\mathrm{c}$, the logistics enterprise's income increases to $\mathrm{V}+\mathrm{c}$.

(4)When the government does not encourage high-quality development and the logistics enterprises implement high-quality development, enterprises still have to pay a certain high-quality development cost. $p$ represents the difference between high-quality development costs and benefits. Therefore, the short-term logistics enterprise income becomes V-p, but it has no big impact on the government, and the government's income is still $\mathrm{U}$.

(5)Assume that $\mathrm{m}, \mathrm{n}, \mathrm{c}, \mathrm{p}>0$ and $\mathrm{m}, \mathrm{n}>\mathrm{c}$, for the long-term development of logistics enterprises, high-quality development is better than no high-quality development.

From the above analysis, the payment matrix of the government and logistics enterprises is shown in Table 1 .

Table1. Payment matrix of governments and logistics enterprises

\begin{tabular}{|c|cc|}
\hline \multirow{2}{*}{ governments } & \multicolumn{2}{|c|}{ logistics enterprises } \\
\cline { 2 - 3 } & implement $(y)$ & do not implement $(1-y)$ \\
\hline encourage $(x)$ & $(U-c+m, V+c+n)$ & $(U-c, V+c)$ \\
\hline Do not encourage $(1-x) \quad(U, V-p)$ & $(U, V)$ \\
\hline
\end{tabular}

\section{EVOLUTIONARY GAME MODEL ANALYSIS}

Through the assumptions and income matrix, the government implements strategy that encourages the high quality development of logistics enterprise, and the government's expected benefits: $\mathrm{U}_{\mathrm{Gl}}=\mathrm{y}(\mathrm{U}-\mathrm{c}+\mathrm{m})+(1-\mathrm{y})(\mathrm{U}-\mathrm{c})$, If the government does not encourage the high-quality development of logistics enterprise, the government's expected benefits: $\mathrm{U}_{\mathrm{G} 2}=\mathrm{yU}+(1-\mathrm{y}) \mathrm{U}$,Therefore, the average expected income of the government players: $\overline{\mathrm{U}}_{\mathrm{G}}=\mathrm{xU}_{\mathrm{Gl}}+(1-\mathrm{x}) \mathrm{U}_{\mathrm{G} 2}$.

In the same way, the expected return of logistics enterprises adopting high-quality development strategies: $\mathrm{U}_{\mathrm{E} 1}=\mathrm{x}(\mathrm{V}+\mathrm{c}+\mathrm{n})+(1-\mathrm{x})(\mathrm{V}-\mathrm{p})$, Expected benefits 
of logistics enterprises that do not adopt high quality development strategies: $\mathrm{U}_{\mathrm{E} 2}=\mathrm{x}(\mathrm{V}+\mathrm{c})+(1-\mathrm{x}) \mathrm{V}$, Average expected revenue for the entire cluster logistics

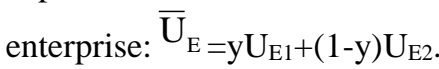

The dynamic equation of replication in evolutionary stable equilibrium [10]:

$\mathrm{Dx} / \mathrm{dt}=\mathrm{x}(\mathrm{Us}-\overline{\mathrm{U}})$

In the formula: $\mathrm{x}$ is the ratio of the strategy s used by the player in a population; Us is the expected benefit of the strategy $\mathrm{s}$ for the player; $\overline{\mathrm{U}}$ is the average benefit of all the strategies in the strategy space is used for the player; $\mathrm{dx} / \mathrm{dt}$ is The player adopts the rate of change of the strategy over time.

According to the replication dynamic equation (1), the government encourages the logistics enterprise to develop high-quality replication dynamic equations as:
$\mathrm{Dx} / \mathrm{dt}=\mathrm{x}\left(\mathrm{U}_{\mathrm{G}^{-}} \overline{\mathrm{U}}_{\mathrm{G}}\right)=\mathrm{x}(1-\mathrm{x})(\mathrm{ym}-\mathrm{c})$

In the same way, it can be concluded that the replication dynamic equation of high-quality development of cluster logistics enterprises is:

$D y / d t=y\left(U_{E 1^{-}} \bar{U}_{E}\right)=y(1-y)(x n+x p-p)$

Through the equations (2) and (3), the equilibrium points of the entire evolutionary game can be calculated as $(\mathrm{x}, \mathrm{y}):(0,0),(1,0),(0,1),(1,1)$ and $(\mathrm{p} /(\mathrm{p}+\mathrm{n}), \mathrm{c} / \mathrm{m})$. Based on the algorithm proposed by Friedman [11], the stability analysis of the equilibrium points is obtained by analyzing the local stability of the J matrix. Find the (2), (3) two formulas on the partial derivatives of $x$ and $y$, and get the $\mathrm{J}$ matrix:

$\mathbf{J}=\left[\begin{array}{cc}(1-2 x)(m y-c) & x(1-x) m \\ y(1-y)(n+p) & (1-2 y)[(n+p) x-p]\end{array}\right]$

Table 2. Local stability analysis of dynamic systems

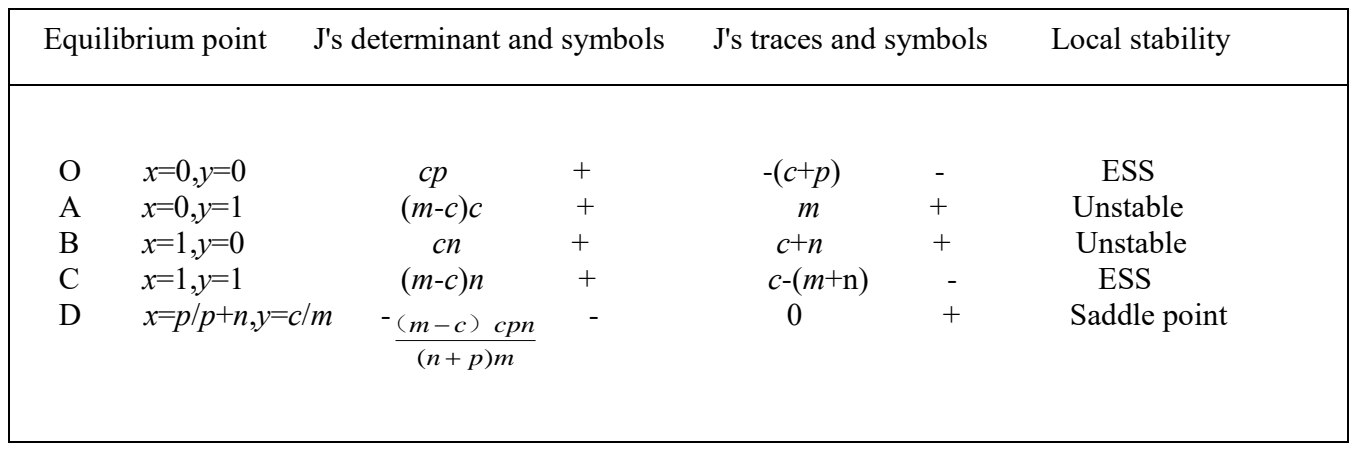




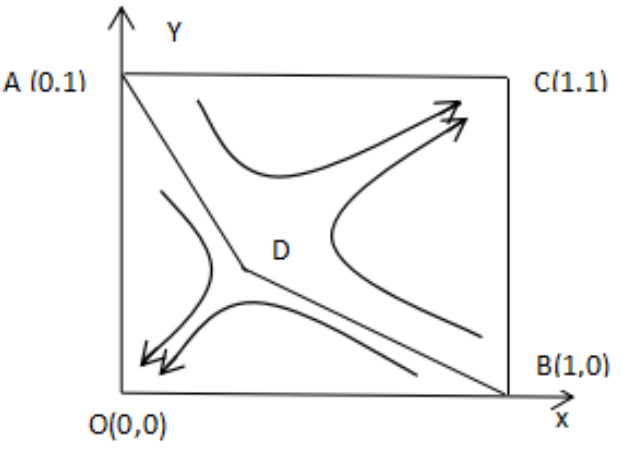

Figure 1

The determinant, trace values, and symbols of the five equalization points can be calculated by analyzing the $\mathrm{J}$ matrix. Then to determine the local stability of the five equilibrium points to the entire system. The calculation results are shown in Table 2.

It can be obtained from Table 2 that two of the five equilibrium points are stable. Two of the other three points are unstable and the other is the saddle point. The dynamic copy phase map shown in Figure 1 can be drawn through these five points.

It can be seen from the observation in Figure 1. The system has two stable evolution strategies. We can adjust the system convergence to two stable points by adjusting the position of the initial value $\mathrm{D}$ point.

\section{MODEL PARAMETER ANALYSIS}

\subsection{Parameters $m, n$}

$m, n$ is the excess return. When $m$ is large, $\mathrm{D}$ moves downward. It can be seen from Fig. 1, and the possibility that the system evolves to the point $\mathrm{C}$ increases. The same is true for the same change in $n$. The above analysis can be obtained: whether it is the government or logistics enterprises, the greater the gains from high-quality development behavior, the greater the possibility that the government encourages the high-quality development and the greater the motivation for logistics enterprises. This has formed a win-win situation for the government-logistics enterprises.

\subsection{Parameter $c$}

$c$ refers to a kind of cost about financial support policy made by the government to encourage logistics enterprises. When $\mathrm{c}$ increases, the more subsidies that logistics enterprises receive, the corresponding reduction of the inherent risks of logistics enterprises, the greater the possibility that logistics enterprises choose to implement high-quality development, they will also get more revenue, the values of $m$ and $n$ increase, and $\mathrm{D}$ is closer to point $\mathrm{C}$, and the possibility that the system evolves to point $\mathrm{C}$ is greater.

\subsection{Parameter $p$}

$p$ indicates that the costs incurred by logistics enterprises in their own high quality development. When $p$ increases, the saddle point $\mathrm{D}$ moves to the left, the possibility that the logistics enterprise carries out high-quality technical development becomes smaller. The higher the development cost of logistics enterprises, the more likely it does not implement high-quality development behavior. Encourage policies can reduce development costs, and the game will converge to equilibrium state $\mathrm{C}$.

\section{CONCLUSIONS AND RECOMMENDATIONS}

\subsection{Conclusions}

By establishing a dynamic evolutionary game model, this paper obtains the necessity of the government to encourage logistics enterprises to carry out high-quality development behaviors. At the same time, the positive effects brought by the high-quality development behavior will prompt the government to further improve the high-quality development encouragement policies of logistics enterprises. However, the high-quality development process is essentially a continuous process. The institutional environment built by the government does not necessarily promote the high-quality development of logistics enterprises from the very beginning; the government must constantly adjust its own behavior according to the response of logistics enterprises.

\subsection{Recommendations}

The government should establish relevant policy systems under the overall layout plan, and establish corresponding system specifications for the location of logistics enterprises; enhance the high-quality development by introducing advanced logistics technology. Now smart logistics has a major trend in the development of the logistics industry; cultivate a large number of high-quality logistics talents. The major universities in Shanxi in China should pay attention to cultivating high-quality logistics talents. Strengthen the training of employees in the existing logistics industry; promote the high-quality development of the logistics industry.

\section{ACKNOWLEDGMENTS}

This research was financially supported by the Shanxi philosophy and social science research project (Grant No. 2019B119), the Education and Teaching Reform Research Project of Shanxi University of Finance and Economics (Grant No. 2012110). 


\section{REFERENCES}

[1] Gao Pumei, Zhan Jun. Logistics Industry Cluster and Industrial Structure Change in the Yangtze River Delta Urban Agglomeration_-Based on Grey Correlation Analysis.Resource Development \& Market,2019,35(02):149-155.

[2] Li Zhuo. Analysis of the Factors Affecting the Performance of High-tech Enterprise Management Team. Modern Business Industry, 2018, 39(16): 67-68.

[3] Wang Hailu. Research on Performance Management of R\&D Staff in High-tech Enterprises. China Business Theory, 2016(21): 56-57.

[4] WEI Guanghui, HUANG Yanning. Analysis of Financing Status and Cost of Small and Micro Enterprises in Anhui Province-Based on the Perspective of National Policy-Oriented Financial Innovation.Journal of Huanggang Normal University, 2017, 37(04):115-120.

[5] Niu Tao. Discussion on the implementation of green logistics management strategy in low-carbon economy environment. Modern Marketing (late issue), 2019 (01): 91.
[6] Li Dengjie. Research on the Development of Green Circulation Logistics System in Shandong Province. Modern Business and Trade, 2018, 39(25): 15-17.

[7] Ma Chunqian, Zhang Xueyu. Review and Prospect of Green Logistics Management Research. Economic Outlook of the Bohai Sea, 2018 (08): 57-59.

[8] He Liming. Trends in the development of China's logistics industry and supply chain in the new era. Modern Logistics News, 2017-12-13 (A01).

[9] DAVID B, RAYOUSSE J, LUO L. Optimization of thermoelectric heat pumps by operating condition management and heat exchanger design. Energy Conversion and Management, 2012(60): 125-133.

[10] Wang Xuemin. Applied multivariate analysis. Shanghai: Shanghai University of Finance and Economics Press, 1999.

[11] FRIEDMAND. EvolutionaryGames in Economics. Eeonomictri. Ca, 1991 (59): 637-666. 